\title{
Influence of the Cathode Material Properties in Reducing the Back- Bombardment Effect in Thermionic RF Gun
}

\author{
$\operatorname{AUTHOR(S):~}$
}

Bakr, Mahmoud; Ohgaki, Hideaki

\section{CITATION:}

Bakr, Mahmoud ... [et al]. Influence of the Cathode Material Properties in Reducing the Back-Bombardment Effect in Thermionic RF Gun. IEEE Transactions on Electron Devices 2018, 65(11): 5053-5061

ISSUE DATE:

2018-11

URL:

http://hdl.handle.net/2433/243257

\section{RIGHT:}

(C) 2018 IEEE. Personal use of this material is permitted. Permission from IEEE must be obtained for all other uses, in any current or future media, including reprinting/republishing this material for advertising or promotional purposes,

creating new collective works, for resale or redistribution to servers or lists, or reuse of any copyrighted component of this work in other works.; This is not the published version. Please cite only the published version.; この論文は出版社版

でありません。引用の際には出版社版をご確認ご利用ください。 


\title{
Influence of the Cathode Material Properties in Reducing the Back Bombardment Effect in Thermionic RF Gun
}

\author{
Mahmoud Bakr (member), and Hideaki Ohgaki, (member)
}

\begin{abstract}
The effect of back bombardment (BB) electrons is considered one of the main obstacles for extensive use of thermionic RF guns. Ten hexaboride materials named $(\mathrm{Ca}, \mathrm{Sr}, \mathrm{Ba}$, $\mathrm{La}, \mathrm{Ce}, \mathrm{Pr}, \mathrm{Nd}, \mathrm{Sm}, \mathrm{Eu}$, and Gd) $\mathrm{B}_{6}$ are investigated in this work to survey the effect of the cathode material on reducing $B B$ electrons and compare them with $\mathrm{LaB}_{6}$ (which is widely used as a thermionic cathode). A numerical model was used to conduct this study. Besides the numerical calculations; an experiment has been performed to determine the work functions of $\mathrm{CeB}_{6}$ and $\mathrm{LaB}_{6}$. The results from the numerical calculations revealed that $\mathrm{Ba}, \mathrm{Ca}$, and Nd) $B_{6}$ are less affected by BB electrons: 42, 50, and $59 \%$ respectively, compared with $\mathrm{LaB}_{6}$, for low beam current applications. In contrast, for high beam current duties, (Nd, Ce, and $\mathrm{Sm}) \mathrm{B}_{6}$ have minimum influence by $\mathrm{BB}$ electrons compared with other hexaborides. The study concluded that BB electrons are strongly affected by the properties of the cathode material, especially thermionic emission and material density. Moreover, the study suggests that it is worthwhile to prepare $\mathrm{BaB}_{6}, \mathrm{CaB}_{6}$, $\mathrm{NdB}_{6}$, and $\mathrm{SmB}_{6}$ as cathode materials, then to subject them to a real experimental test using thermionic RF gun to compare their performance and $\mathrm{BB}$ effect against $\mathrm{LaB}_{6}$.
\end{abstract}

Index Terms-Hexaborides, Back bombardment, Work function, RF guns, Thermionic emission, Electron acceleration.

\section{INTRODUCTION}

$\mathrm{W}$ ITHIN the applications of electron accelerators electrons are generated from a cathode and accelerated out of the electron gun to the next acceleration structures. The quality of the generated electron beam is the criterion to judge the electron source employed in the application, such as for on-site research, industrial and medical uses. Radio-frequency (RF) electron guns [1], [2], and electrostatic DC electron guns [3], [4], are world-wide utilized in accelerators facilities. Simple and compact configuration characterizes the RF gun compared to the DC gun. Electrons are generated from the cathode in the RF guns using two methods, photoemission and thermionic emission both named photocathode RF gun (P-RF) and thermionic RF guns (T-RF), respectively. A P-RF gun is capable of producing electron bunches with very low emittance based on laser specifications employed in the system [5]. However, the cost of the laser system and cathode material

Manuscript received June 11, 2018. This work was supported in part by Grant-in-Aid for Scientific Research MEXT, the Ministry of Education, Sports, Science and Technology of Japan. M. Bakr was with the Graduate School of Energy Science, Kyoto University, Kyoto 606-8501, Japan. He is now with the Institute of Advanced Energy, Kyoto University, Kyoto 611-0011, Japan. His permanent address is Physics Department, Faculty of Science, Assiut operation lifetime are critical aspects of operation with this technique. The T-RF gun is competent to produce high-quality electron beam without an expensive laser system by simply applying several watts from DC power supply on the cathode material fixed in the gun end. The T-RF gun cathode is employed as an electron emitter in the Kyoto University Free Electron Laser Facility (KUFEL) [6]. Despite this, the back bombardment (BB) electrons effect, is one of the main obstacles to the wider use of T-RF guns [7]. Briefly, the BB effect is the transient heating of the cathode surface due to electrons emitted late in the RF cycle; these electrons reverse their direction and impact at the cathode surface. As a result, a series of changes occur during the macropulse.

This work emphasizes the T-RF gun and its reliability as a compact electron injector by reducing the $\mathrm{BB}$ electrons effect. Plenty of methods have been proposed for the BB effect reduction in a T-RF gun. For example, one is to modify the applied electric filed inside the gun cavity [8] or to modify the internal design of the gun structure [9], [10]. Another is to mitigate the BB effect by applying an external magnetic field in front of the cathode and modify the cathode shape [7], [11], [12], [13], [14]. More recently, a compensation system for the temperature change in the cathode using an external laser system has been proposed [15]. However, few papers have looked at the influence of the cathode material's properties in reducing the $\mathrm{BB}$ effect [16], [17], [18]. To increase the efficiency of the T-RF gun, it is preferable to reduce the BB effect from the source by minimizing the change in the cathode temperature and the current density in the cathode surface. From this standpoint, the selection of the cathode material with less BB effect for the T-RF gun becomes a critical issue. Due to the difficulty to measure the BB electrons directly, in our study a simulation technique is used to understand such phenomenon, and a numerical evaluation method is applied to show the influence of the cathode material in the reduction of the BB effect.

In this study, the properties of 10 hexaborides $\left(\mathrm{RAB}_{6}\right)$ are investigated and compared with $\mathrm{LaB}_{6}$, which is already in use as a cathode material to protect against $\mathrm{BB}$ electrons in most $\mathrm{T}$ $\mathrm{RF}$ gun facilities worldwide. The elements are $(\mathrm{Ca}, \mathrm{Sr}, \mathrm{Ba}, \mathrm{La}$, $\mathrm{Ce}, \mathrm{Pr}, \mathrm{Nd}, \mathrm{Sm}, \mathrm{Eu}$, and Gd) $\mathrm{B}_{6}$. Two of these materials ( $\mathrm{LaB}_{6}$

University, Asyut 71516, Egypt (e-mail: bakrarby.mahmoud.8u@kyotou.ac.jp, m_a_elsherif@yahoo.com).

H. Ohgaki is with the Institute of Advanced Energy, Kyoto University, Kyoto 611-0011, Japan e-mail: ohgaki@iae.kyoto-u.ac.jp). 
and $\mathrm{CeB}_{6}$ ) are fabricated as a cathode material for the T-RF gun, and then the emission properties are measured experimentally. The structure of this article is arranged as follows: Section II presents the selection of the cathode materials. Section III is focused on explaining the evaluation technique used to understand the $\mathrm{BB}$ effect and the influence of the cathode material in reducing the BB effect. Finally, sections IV and V present the results, discussion, and conclusions of the analysis.

\section{SELECTION OF CATHODE MATERIALS}

The emission properties of the cathode material are critical for future applications of T-RF gun [19]. An extended operational lifetime in a high emission rate, low work function, and low evaporation rate are mandatory for stable use of a cathode material in a T-RF gun for both research and industrial applications. These unique properties are obtainable from single crystals of $\mathrm{RAB}_{6}$. The first study on $\mathrm{RAB}_{6}$ goes back to Lafferty in 1951, who revealed that hexaborides could be candidate materials as electron emitters for high duty applications compared with carbides [20]. Since then, the emission properties of $\mathrm{RAB}_{6}$ materials have been intensively explored.

In the cubic structure of the $\mathrm{RAB}_{6}$, the rare-earth or alkaline atom occupies the center core surrounded with octahedral borides atoms as seen in Fig. 1. This structure gives $\mathrm{RAB}_{6}$ materials unique physical and chemical characteristics of hardness, low electronic work function, high melting point, high strength, high chemical and thermal stability and the possibility of recovery after poisoning. Many methods have been invented to prepare single crystals of $\mathrm{RAB}_{6}$ for the field of cathode materials and electron emission applications. The size and purity of the crystal are mainly determining in which application the crystal will be used. For instance, the chemical vapor deposition method [21] is suitable for thin film material preparation, while, for large crystals of $\mathrm{RAB}_{6}$, the floating zone [22], and the aluminum flux [23] methods are more appropriate. The performance of the crystal as an electron emitter is characterized by the purity of prepared crystal, surface conditions, and vacuum level upon crystal activated for operation. Therefore, in some works the measured values of the emission properties, like the material work function of $\mathrm{RAB}_{6}$ are diverse, for example, 2.30-2.87 eV for $\mathrm{LaB}_{6}$.

The $\mathrm{RAB}_{6}$ materials used in this study are $(\mathrm{Ca}, \mathrm{Sr}, \mathrm{Ba}, \mathrm{La}$, $\mathrm{Ce}, \mathrm{Pr}, \mathrm{Nd}, \mathrm{Sm}, \mathrm{Eu}$, and $\mathrm{Gd}$ ) $\mathrm{B}_{6}$. These materials have been explored as electron emitters, and emission properties have

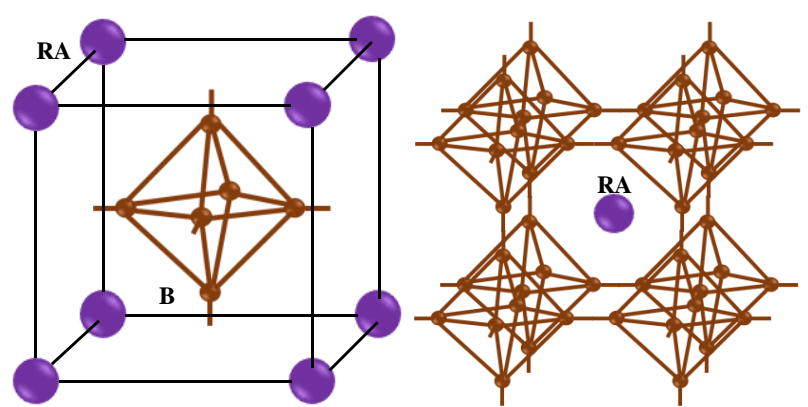

Fig. 1. Hexaborides $\left(\mathrm{RAB}_{6}\right)$ crystal structure, $\mathbf{B}$ atoms are forming a 3D framework surround $\mathbf{R A}$ atom.

been determined. $\mathrm{LaB}_{6}, \mathrm{CeB}_{6}$, and $\mathrm{SmB}_{6}$ are candidates for several applications such as high-energy optical systems, sensors for high-resolution detectors, electrical coatings for resistors, etc. [24]. In turn, $\mathrm{NdB}_{6}$ and $\mathrm{PrB}_{6}$ have shown great applications prospects as thermionic and field emission cathode materials [25], [26], and $\mathrm{CaB}_{6}, \mathrm{SrB}_{6}, \mathrm{BaB}_{6}, \mathrm{EuB}_{6}$, and $\mathrm{GdB}_{6}$ have numerous physical properties which have been explored as electron emitters [20] and ferromagnetic materials [27], [28]. It is said that doping of $\mathrm{La}$ or $\mathrm{Ce}$ into other $\mathrm{PrB}_{6}, \mathrm{NdB}_{6}$ and $\mathrm{GdB}_{6}$ results in reducing the system work function and enhance the compounds emission [29]. The features of explored hexaborides are given in Table I. Excluding $\mathrm{LaB}_{6}$ and $\mathrm{CeB}_{6}$ there is no work reported using the investigated materials as TRF gun cathode until writing this paper.

Due to their high electron emission, Ba dispenser tungstenbase cathodes, which were fabricated from porous tungsten impregnated with $\mathrm{xBaO} \cdot \mathrm{yCaO} \cdot \mathrm{Al}_{2} \mathrm{O}_{3}$ (so-called W-I cathode), were used as cathodes for KUFEL facility until 2007, but, due to the considerable BB electrons, it was difficult to get a stable electron beam in long pulse duration for more than $1 \mu$ s. On the other hand, $\mathrm{LaB}_{6}$ has less impact by $\mathrm{BB}$ electrons compared to W-I cathode. Therefore, it replaced W-I as a cathode material for KUFEL RF gun. As a result, longer macropulses with higher beam current were produced [17]. Simulation has been performed to compare the effect of $\mathrm{BB}$ electrons between $\mathrm{LaB}_{6}$ and $\mathrm{CeB}_{6}$. The results revealed that $\mathrm{CeB}_{6}$ has $20 \%$ less impact by $\mathrm{BB}$ electrons compared to $\mathrm{LaB}_{6}[18]$. Based on this results, single crystals of $\mathrm{LaB}_{6}$ and $\mathrm{CeB}_{6}$ with $1.8 \mathrm{~mm}$ diameters, prepared using the floating zone method, were purchased to compare the $\mathrm{BB}$ effect experimentally. Before insertion these two cathodes to the RF gun, the cathodes were subjected to an experimental test to determine the emission properties using a table diode stand. The experimental setup and results of this test are presented herein.

TABLE I

HEXABORIDE PARAMETERS USED IN THE EVALUATION TECHNIQUE

\begin{tabular}{lllllllllll}
\hline \hline Parameter & $\mathrm{CaB}_{6}$ & $\mathrm{SrB}_{6}$ & $\mathrm{BaB}_{6}$ & $\mathrm{LaB}_{6}$ & $\mathrm{CeB}_{6}$ & $\mathrm{PrB}_{6}$ & $\mathrm{NdB}_{6}$ & $\mathrm{SmB}_{6}$ & $\mathrm{EuB}_{6}$ & $\mathrm{GdB}_{6}$ \\
\hline Work function: $\mathrm{eV}$ & $2.86^{\mathrm{a}}$ & $2.67^{\mathrm{a}}$ & $3.45^{\mathrm{a}}$ & $2.79^{\mathrm{b}}$ & $2.85^{\mathrm{b}}$ & $2.73^{\mathrm{c}}$ & $3.04^{\mathrm{d}}$ & $2.76^{\mathrm{e}}$ & $4.03^{\mathrm{d}}$ & $2.62^{\mathrm{d}}$ \\
${\text { Richardson Const.: } \mathrm{Acm}^{-2} \mathrm{~K}^{-2}}^{\text {Material density: } \mathrm{gcm}^{-3}}$ & 2.6 & 0.14 & 16 & 120.4 & 120.4 & 120.4 & 120.4 & 120.4 & 120.4 & 120.4 \\
Molecular weight: gmol $^{-1}$ & 2.45 & 3.39 & 4.36 & 4.72 & 4.79 & 4.80 & 4.91 & 5.06 & 4.95 & 5.27 \\
Eff. atomic number & 104.95 & 152.49 & 202.19 & 203.78 & 204.99 & 205.78 & 209.11 & 215.23 & 216.83 & 222.17 \\
Eff. molecular weight: $\mathrm{gmol}^{-1}$ & 22.52 & 53.73 & 93.19 & 94.74 & 96.04 & 97.06 & 99.76 & 104.86 & 106.43 & 110.51 \\
Thermal conductivity $\mathrm{Wm}^{-1} \mathrm{~K}^{-1}$ & 39.16 & 42.03 & 44.77 & 47.70 & 33.89 & 41.01 & 47.28 & 13.81 & 23.01 & 20.50 \\
Melting temperature: $\mathrm{K}$ & 2508 & 2508 & 2543 & 2483 & 2463 & 2483 & 2610 & 2673 & 2200 & 2373 \\
\hline \hline
\end{tabular}

- $\quad$ a from [20], b from [present work], c from [26], d from [29], e from [25] 


\section{Methodology OF RESEARCH}

\section{A. BB phenomenon}

Electrons are emitted from the cathode surface, after heating up to several watts, which run across accelerating field in only $1 / 2$ RF cycle inside the cavity to be extracted from the gun aperture. A fraction of these electrons is emitted late in each RF cycle. They cannot leave the cavity before the field's direction is changed. Once this happens, the electrons turnover and accelerate back to the cathode surface. These electrons gain energy from the inversed accelerating field, so their energy is deposited at the cathode surface. Finally, this energy is converted into heat in the cathode surface rising its temperature during the macropulse.

The electron beam extracted from the T-RF gun has a macropulse and micropulse structures. The micropulse is repeated in a picosecond scale, and the macropulse is the integration of the micropulses and has $\sim \mathrm{Hz}$ repetition rate (350 ps and $1 \mathrm{~Hz}$, for KUFEL) [6]. When the BB electrons hit the cathode surface, the kinetic energy of electrons transfer to thermal energy by interaction with electronic structure in the cathode material, and then lose its energy as heat. The deposited heat has the same structure as electrons, Fig. 2(a). Cathode temperature increases every macropulse with $\Delta \mathrm{T}_{\text {Macro, }}$, and then after macropulse ends, it gradually decreases. This process happens periodically with a specific repetition rate. The increase and decrease of the cathode temperature cause an increase in the average cathode temperature $\Delta \mathrm{T}_{\text {Ave }}$. The rise of

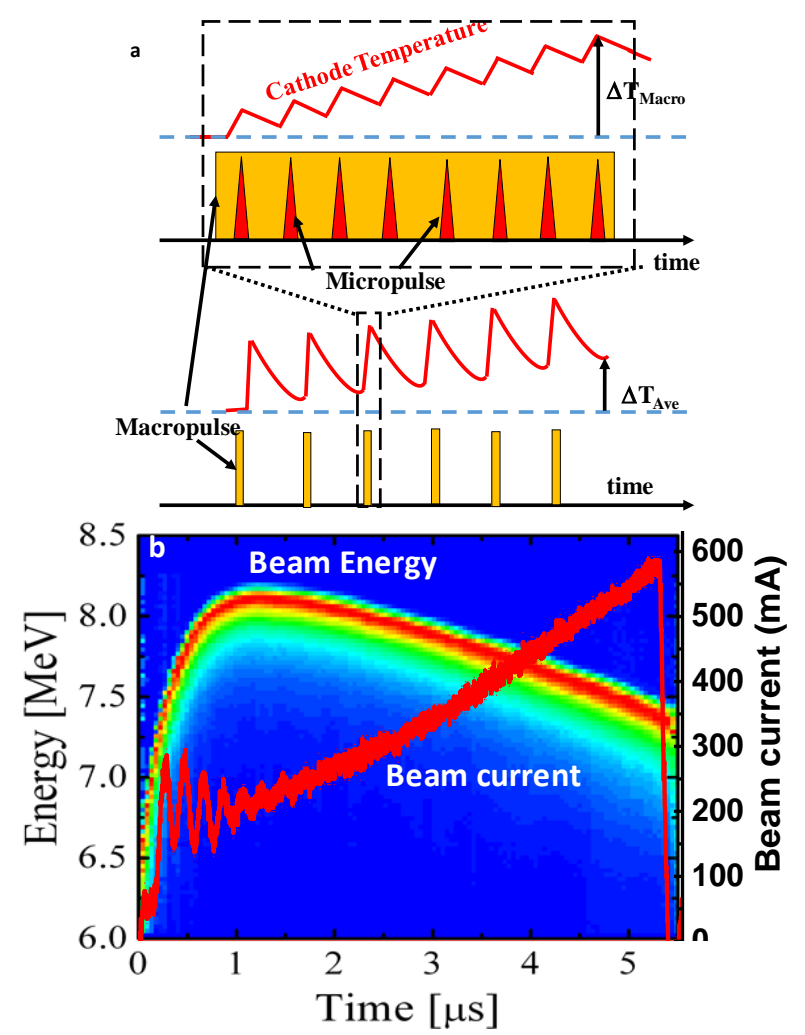

Fig. 2. (a) Schematic image of cathode heating by BB electrons, $\Delta \mathrm{T}_{\text {Macro, }}$, and $\Delta \mathrm{T}_{\mathrm{Ave}}$ are temperature elevation during the macropulse, and average temperature rise, (b) the ramping of beam current and drops of electrons beam energy during the macropulse.
$\mathrm{T}_{\mathrm{Ave}}$ is not a severe problem and is easily controlled by adjusting the cathode heater power using a cathode heater control system based on the extracted charge from the cathode surface [30]. However, the change of $\Delta \mathrm{T}_{\text {Macro }}$ during the macropulse is hard to be controlled by adjusting the cathode heater power. The shift in $\Delta \mathrm{T}_{\text {Macro }}$ introduces ramping of the emitted current density. As a direct result of increasing the beam current the applied cavity voltage decrease, and hence the electron beam energy drops from its nominal target value due to the beam loading effect. Therefore, the properties of the electron beams in the following acceleration are dramatically affected. Fig. 2(b), shows an experimental measurement for the beam current elevation and beam energy deterioration during a $5 \mu$ s pulse interval.

\section{B. Evaluation technique}

In this study, simulation codes have been used to get an overview picture and understand the $\mathrm{BB}$ electrons trajectory and factors affecting its attitude, like cavity voltage, RF pulse shape, extracted beam current, cathode diameter, etc. Two particle simulation codes were used for this purpose, PARMELA [31], and KUPLAI [32] to trace the BB electrons inside the gun's cavity. The gun used to drive the KUFEL facility consists of 4.5 cells in a cavity with a length of $30-\mathrm{cm}$, operated in S-band frequency and driven by a $10 \mathrm{MW}$ RF klystron. The gun can provide up to $10 \mathrm{MeV}$ electron beam, which is generated from a thermionic cathode, fixed in the center cylindrically flat half-cell.

BB electrons lose a stable fraction of its energy through collisions inside the material and a significant fraction just before the complete stop, following Bragg's curve. The influence of the cathode material on reducing the BB electrons in this study is performed using a semi-empirical equation [33], for particles with energy between $0.3 \mathrm{keV}$ and $30 \mathrm{MeV}$, to identify the interaction between $\mathrm{BB}$ electrons and the electronic structure of the cathode material, through its density. The rate of electrons penetrated inside the material (stopping range) is calculated using equation $1[33]$ :

$R(\tau)=\frac{b_{1}}{\rho}\left[\frac{\ln \left(1+b_{2} \tau\right)}{b_{2}}-\frac{b_{3} \tau}{1+b_{4} \tau^{b_{5}}}\right]$.

$\mathrm{R}(\mathrm{m})$ is the distance penetrated by electrons inside the cathode before the electron loses all of its energy and comes to rest, and $\tau$ (electron rest units) is the incident kinetic energy of electrons. $\rho\left(\mathrm{kgm}^{-3}\right)$ is the material density, $b_{i}(\mathrm{i}=1,2 \ldots, 5)$ are constants for every material and defined by a simple function of atomic number $\mathrm{Z}$ and weight $\mathrm{A}$ as:

$b_{1}=\frac{2.335 A}{Z^{1.209}}, \quad b_{2}=0.000178 Z$,

$b_{3}=0.9891-0.000301 Z$,

$b_{4}=1.468-0.0118 Z, \quad b_{5}=\frac{1.232 \mathrm{~A}}{Z^{0.109}}$,

for a compound, values of $Z$ and $A$ are replaced by the effective values of $Z_{\text {eff }}$ and $A_{\text {eff }}$ as [33]:

$$
Z_{\text {eff }}=\sum_{i} f_{i} Z_{i}, A_{e f f}=\frac{Z_{\text {eff }}}{(Z / A)_{e f f}}, \quad(Z / A)_{e f f}=\sum_{i} \frac{f_{i} Z_{i}}{Z_{i}},
$$

$f_{i}$ is defined as the fraction by weight of compound elements, $\mathrm{Z}_{\mathrm{i}}$ 
and $\mathrm{A}_{\mathrm{i}}$ are an atomic number and atomic weight of individual components of the compound. $Z_{\text {eff }}$ and $A_{\text {eff }}$ of cathode materials involved in this study are calculated and given in Table 1.

Energy deposition from particles losing its energy by struggling inside a material can be defined as: "the change of particle energy $\Delta E(\mathrm{eV})$ divided by the traveled range $\Delta R(\mu \mathrm{m})$ inside the material and written in the form $(-\Delta E / \Delta R)\left(\mathrm{eV} \mu \mathrm{m}^{-1}\right)$ [33]. Heat deposition in cathode surface has the same BB electrons distribution and affected by the same factors that affect BB electrons mentioned above. Therefore, in this study, a specific condition is considered to determine the influence of the cathode material on reducing BB electrons.

A numerical model was used to determine the elevation of the cathode temperature, current density along with the shift in cavity voltage and beam energy by solving two differential equations. The first one is the RF gun equivalent circuit and the second one is a one-dimensional thermal diffusion equation for the thermionic cathode. More details are found in [17]. A $2 \mathrm{~mm}$ thickness cathode is assumed in the model, this thickness is modeled as 20000 thin disks, one end is facing the gun cavity and the second is connected to the cathode heater, Fig. 3. Within the first $1 / 2 \mathrm{RF}$ cycle, the cathode is in thermal equilibrium. The heat input from the cathode heater is in balance with the radiative heat loss from the cathode surface to the cavity. In the second $1 / 2 \mathrm{RF}$ cycle, $\mathrm{BB}$ electrons are hit on the cathode surface. Therefore, the additional heat flux is given to the cathode surface, then penetrate the cathode surface, depending on the energy of the BB electrons. Rapid change in the cathode temperature occurs during the macropulse, and this change is calculated from the thermal diffusion equation below:

$K_{1} \frac{\partial T(z, t)}{\partial t}-K_{2} \frac{\partial^{2} T(z, t)}{\partial z^{2}}-Q_{\mathrm{b}}\left(z, t, V_{\mathrm{c}}, J_{\mathrm{c}}\right)=0$.

where $K_{1}=C \rho V$ and $K_{2}=\lambda$ are the thermal parameters of the cathode material, $\mathrm{C}\left(\mathrm{Jkg}^{-1} \mathrm{~K}^{-1}\right), \mathrm{V}\left(\mathrm{m}^{3}\right)$ and $\lambda\left(\mathrm{Wm}^{-1} \mathrm{~K}^{1}\right)$ are the cathode specific heat capacity, volume, and thermal conductivity, while $\mathrm{z}(\mathrm{m})$ is the depth of cathode from the surface in which the electrons can reach. $Q_{b}$ is the heat input from BB electrons, which depends on current density $J_{c}\left(\mathrm{Acm}^{-}\right.$ ${ }^{2}$ ) emitted from the cathode, and cavity voltage $V_{C}(\mathrm{~V})$. The energy and heat distribution of BB electrons used in this step is prepared in advance using the PARMELA code. Parameters used in this model for the RF gun are given in Table II.

When the cathode temperature increases, the number of emitted electrons increases or, the cathode current density is shifted up. Richardson-Dushman equation is used to determine the change of the current density which is given as [34]:

$$
J=A T^{2} \exp (-\phi / k T) \text {. }
$$

TABLE II

KUFEL RF GUN PARAMETERS USED IN THE PRESENT STUDY

\begin{tabular}{ll}
\hline \hline Parameter & Values \\
\hline RF power: MW & 8 \\
Macropulse duration: $\mu$ s & 6 \\
Resonance frequency: $\mathrm{GHz}$ & 2.856 \\
Coupling coefficient: $\beta$ & 12500 \\
R/Q: $\Omega$ & 980 \\
Accelerating mode & $\pi$ \\
Cathode diameter: $\mathrm{mm}$ & 2 \\
\hline \hline
\end{tabular}

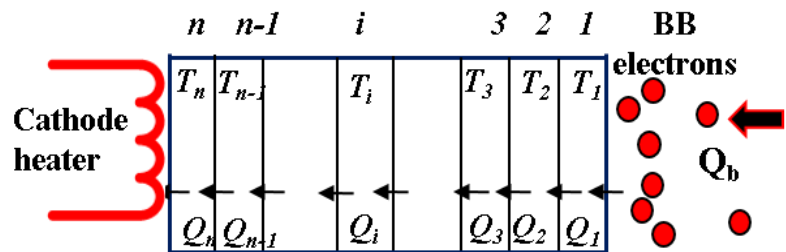

Fig. 3. Schematic image of the cathode shape as modeled in the model. where $\mathrm{A}$ and $\mathrm{k}$ are Richardson and Plank constants with values of $120.4 \mathrm{Acm}^{-2} \mathrm{~K}^{-2}$ and $8.62 \times 10^{-5} \mathrm{eVK}^{-1}$, respectively. $\phi(\mathrm{eV})$ is the material's work function, and $\mathrm{T}(\mathrm{K})$ is the cathode operating temperature.

\section{A. Experimental setup for $\mathrm{LaB}_{6}$ and $\mathrm{CeB}_{6}$ test}

Two single crystals of $\mathrm{LaB}_{6}$ and $\mathrm{CeB}_{6}$ cathodes were experimentally tested using a test stand diode to determine the materials work functions. The current-voltage characterization curves at different cathode temperatures of 1700, 1800, and $1900 \mathrm{~K}$, are measured by applying a negative voltage, in the range between 15 to $50 \mathrm{KV}$. These are placed on the cathode base, and the beam is collected using a grounded anode at 2.1 $\mathrm{cm}$ distance from the cathode surface. The pressure conditions of the experiment are at a level higher than $\sim 10^{-8} \mathrm{~Pa}$. Temperatures were selected which cover a wide range of the real operational conditions of the KUFEL gun.

\section{RESULTS AND DISCUSSION}

\section{A. Simulation predictions}

Assuming the same nominal operational condition to generate MIR-FEL in KUFEL facility, BB electrons were traced, using PARMELA code, a general view of the simulation results are depicted in Fig. 4. The relation between the heat deposition and the range inside the cathode surface is plotted at different current densities - see Fig. 4(a). The BB electrons' distribution on the cathode surface is plotted in Fig. 4(b), some observations and comments on simulation results are detailed below:

1) The BB electrons have an energy profile. In Figs. 4(a) and 5 (a), electrons with energy $<100 \mathrm{keV}$ deposit highest heat fraction within $0.1 \mathrm{~mm}$ from the cathode surface. These electrons most likely returned from the first $1 / 2$ cell of RF cavity. The BB electrons with $<600 \mathrm{keV}$ energy, deposit a moderated heat as it penetrates deep inside the cathode $\sim 0.5$ $\mathrm{mm}$. Finally, electrons with energy $>600 \mathrm{keV}$, have limited contribution to heating up the cathode surface, because its percentage is too small - see Fig. 4(b). Thus, its stopping range is high.

2) At constant current density, $20 \mathrm{Acm}^{-2}$, energy of BB electrons increases with increasing the applied cavity field from 30 to $49 \mathrm{MVm}^{-1}$. As a result, the stopping range in the cathode surface increase. Although total deposited charge in the cathode surface is constant, heat deposition increase with increase applied cavity field due to the rise of the electron energies gained from the decelerating cavity field.

3) At constant cavity field, $49 \mathrm{MVm}^{-1}$, heat deposition from the BB electrons increase with the current density, due to increase the total deposited charge in the cathode surface -see Fig. 4(a). 

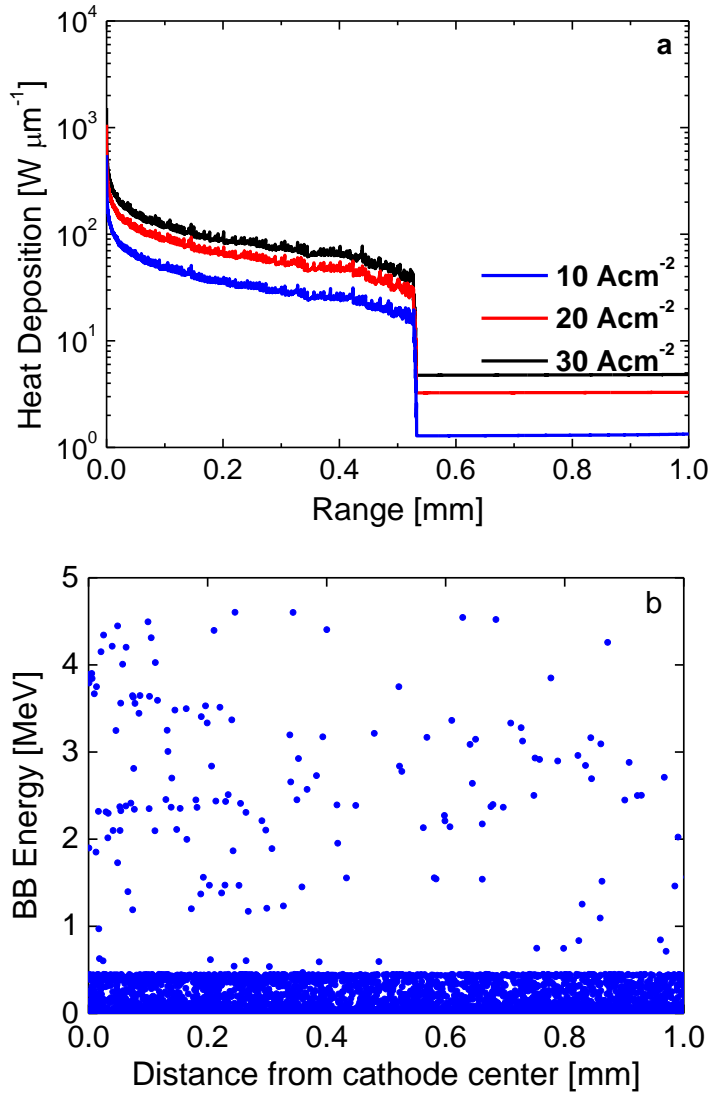

Fig. 4. Simulation results for BB electrons in the RF gun, (a) heat deposition as a function of the emitted current density, (b) BB electron energy distribution on the cathode surface.

The range of $\mathrm{BB}$ electrons is not related to the change of the current density, because the energy of the BB electrons is independent on emitted current density.

4) At constant cavity field $49 \mathrm{MVm}^{-1}$ and current density 20 $\mathrm{Acm}^{-2}$, the distribution of $\mathrm{BB}$ electrons on the cathode surface is almost uniform for low energy electrons. However, electrons with $>600 \mathrm{keV}$, which reflected from $2^{\text {nd }}-5^{\text {th }}$ cells, and received more energy from the decelerating field, are focused near the cathode center, Fig. 4(b).

5) At a constant cavity field and current density for $49 \mathrm{MVm}^{-}$ ${ }^{1}$ and $10 \mathrm{Acm}^{-2}$, respectively, the heat deposition from BB electrons increases in accordance to the cathode radius. This attitude is referred to the increment of the cathode area, which gives more chance to BB electrons with low energy components to make an impact and deposit its energy.

\section{B. Range and heat deposition}

Based on the simulation results presented above, BB electrons with energy below $600 \mathrm{keV}$, have a severe effect on the cathode compared with higher energy ones. Moreover, the fraction of the energetic electrons is negligibly small compared with those in the low regime. Also, these electrons are easily swept-out, by applying an external magnetic field in front of the cathode surface [7]. Given all the above, for convenience, our discussion will center on the BB electrons with energy up to 1 $\mathrm{MeV}$. This will attain greater reliability in the evaluation and easiness to reach our conclusions.

The range and heat deposited from $\mathrm{BB}$ electrons up to $1 \mathrm{MeV}$ were calculated using equation 1 . The estimation is done with
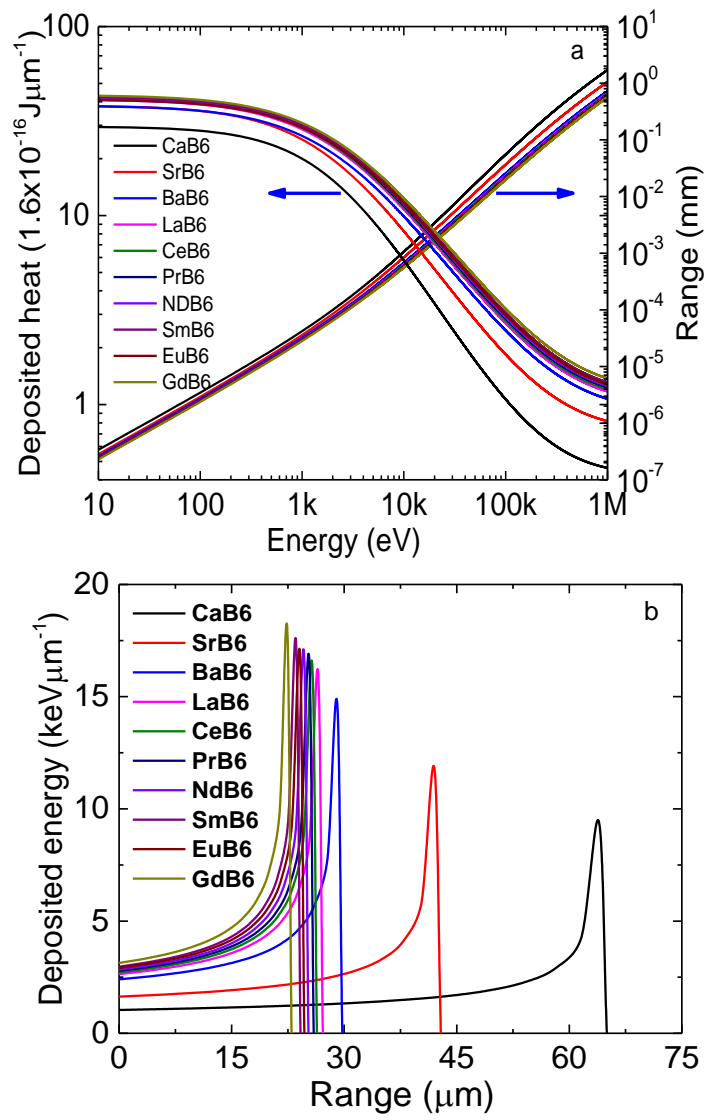

Fig. 5. The range and deposited heat calculated from equation 1, for cathode materials (a), the deposited energy from $100 \mathrm{keV}$ BB electrons and corresponding range (b).

the chosen hexaborides. They are then plotted as a function of the energy of the electron as seen in Fig. 5(a). Also, the deposited energy from $100 \mathrm{keV}$ BB electrons is determined as a function of the stopping range and then plotted in Fig. 5(b). Fig. 5, also shows that apparently, BB electrons travel deeper in $\mathrm{CaB}_{6}$ compared to other materials, and its energy is deposited far inside the cathode. However, BB electrons move a short distance in $\mathrm{GdB}_{6}$ and accumulate considerable heat near the cathode surface. Under the same conditions, the range of $\mathrm{BB}$ electrons decreases from $\mathrm{SrB}_{6}$ to $\mathrm{EuB}_{6}$, whereas collected heat increase. The material densities of the cathode increase from 2.45 to $5.27 \mathrm{gcm}^{-3}$ for $\mathrm{CaB}_{6}$, to $\mathrm{GdB}_{6}$, respectively, while the corresponding range, for $100 \mathrm{keV}$ electrons, is decreasing from 65 to $22 \mu \mathrm{m}$, respectively (see Table I). Such a trend can be explained by the effect of the material density in equation 1 . The range of $100 \mathrm{keV}$ BB electrons in $\mathrm{LaB}_{6}$ and $\mathrm{CeB}_{6}$ are 27 and $26 \mu \mathrm{m}$ respectively; this small difference can be referred to the density difference between the materials $\sim 0.07 \mathrm{gcm}^{-3}$. Comparing the stopping range and the density of between $\mathrm{CaB}_{6}$ and $\mathrm{LaB}_{6}$ material gives 2.4 times and $52 \%$, respectively. For $500 \mathrm{keV}$ BB electrons the stopping range of $\mathrm{CaB}_{6}, \mathrm{LaB}_{6}$, and $\mathrm{CeB}_{6}$ are $0.705,0.281$, and $0.265 \mathrm{~mm}$, which means the range of $\mathrm{CaB}_{6}$ is $\sim 2.5$ times longer than $\mathrm{CeB}_{6}$ and $\mathrm{LaB}_{6}$.

Due to an increase in the interaction cross-section of electrons with microscopic structure of the dense material, BB electrons penetrate a short distance and then deposit high heat (near the surface), while, for light, material electrons move longer and accumulate less heat (far away from the cathode surface). The 
heat deposition near the cathode surface introduces rapid change in cathode temperature and consequently a rapid increase of emitted current density during the macropulse compared with the heat deposited far inside. As a result, one can conclude "from the stopping range and deposited heat power point of view, light material is preferable and expected to have less effect by BB electrons compared with dense materials." These results suggest that using $(\mathrm{Ca}, \mathrm{Sr}, \mathrm{Ba}) \mathrm{B}_{6}$ as a cathode material for T-RF gun will yield a smaller effect by BB electrons compared with other materials.

\section{Emission properties of $\mathrm{LaB}_{6}$ and $\mathrm{CeB}_{6}$}

The characterization curves for $\mathrm{LaB}_{6}$ and $\mathrm{CeB}_{6}$ were measured at 1700,1800 , and $1900 \mathrm{~K}$; then the results are sketched using the Schottky plot by drawing $\log J$ versus $U^{0.5}$. Fig. 6(a) and (b) show these curves, respectively. From the Schottky plot, the current density corresponding to zero applied voltage $\left(\boldsymbol{J}_{0}\right)$ was determined from the tangent of the current density curve at high applied voltage region. Then, the Richardson Dushman formula: $\phi=k T \ln \left(A T^{2} / J_{0}\right)$ was used to determine the work function. The tangent for every curve was plotted, and the corresponding values of $\boldsymbol{J}_{\boldsymbol{0}}$ were estimated for the materials, see Fig. 6.

The work functions for $\mathrm{LaB}_{6}$ are estimated at 1700, 1800, and $1900 \mathrm{~K}$, to be $(2.74,2.77$, and $2.86 \mathrm{eV})$ with an average of 2.79 $\mathrm{eV}$. For $\mathrm{CeB}_{6}$ the corresponding results are $(2.75,2.85$, and 2.96 $\mathrm{eV}$ ), with an average of $2.85 \mathrm{eV}$. These values are in the range of previous studies, for example, $2.91 \mathrm{eV}$ for $\mathrm{LaB}_{6}$ [35]. The slight difference found might be attributable to the purity of the crystals used. The average values reported above are inserted into Table I and used as input parameters for the calculation model in the in next subsection.

\section{Change in the cathode temperature and current density}

The work functions and the Richardson constants for the cathode materials are inserted in equation 5 to plot the ideal emission curves as a function of the cathode temperature (Fig. 7). For the T-RF gun employed in soft duty applications with low peak current requirements $<300 \mathrm{~mA}$, thermionic cathode might be operated with $<10 \mathrm{Acm}^{-2}$ current density. In this study, $5 \mathrm{Acm}^{-2}$ is assumed to be emitted from the cathode before BB electrons hit the cathode surface. The initial temperatures corresponding to the $5 \mathrm{Acm}^{-2}$ current density are determined from Fig. 7. These temperatures are listed in Table III.

Two out of ten of the hexaborides, $\left(\mathrm{SrB}_{6}, \mathrm{EuB}_{6}\right)$ are not able to emit $5 \mathrm{Acm}^{-2}$ before their melting points 2509 and $2200 \mathrm{~K}$, because of the low value of the Richardson's constant for $\mathrm{SrB}_{6}$ and the high working function for $\mathrm{EuB}_{6}$. Thus, those materials are excluded from the next steps. The ramping of the cathode temperature $(\Delta T)$ and current density $(\Delta J)$ from the initial values for eight hexaborides were calculated from the numerical model and shown in Table III. It can be seen from the table that $\Delta \mathrm{T}$ is ranging from $62 \sim 94 \mathrm{~K}$ for $\mathrm{CaB}_{6}$ to $\mathrm{GdB}_{6}$, respectively. This tendency is merely following the cathode materials density growth from $\mathrm{CaB}_{6}$ to $\mathrm{GdB}_{6}$. In contrast, $\Delta \mathrm{T}$ for $\mathrm{LaB}_{6}$ and $\mathrm{CeB}_{6}$ are 79 and $71 \mathrm{~K}$ even with the fact that the density of $\mathrm{LaB}_{6}$ is less than $\mathrm{CeB}_{6}$. This tendency can be explained by thermal conductivity differences between the materials as shown in Table I.
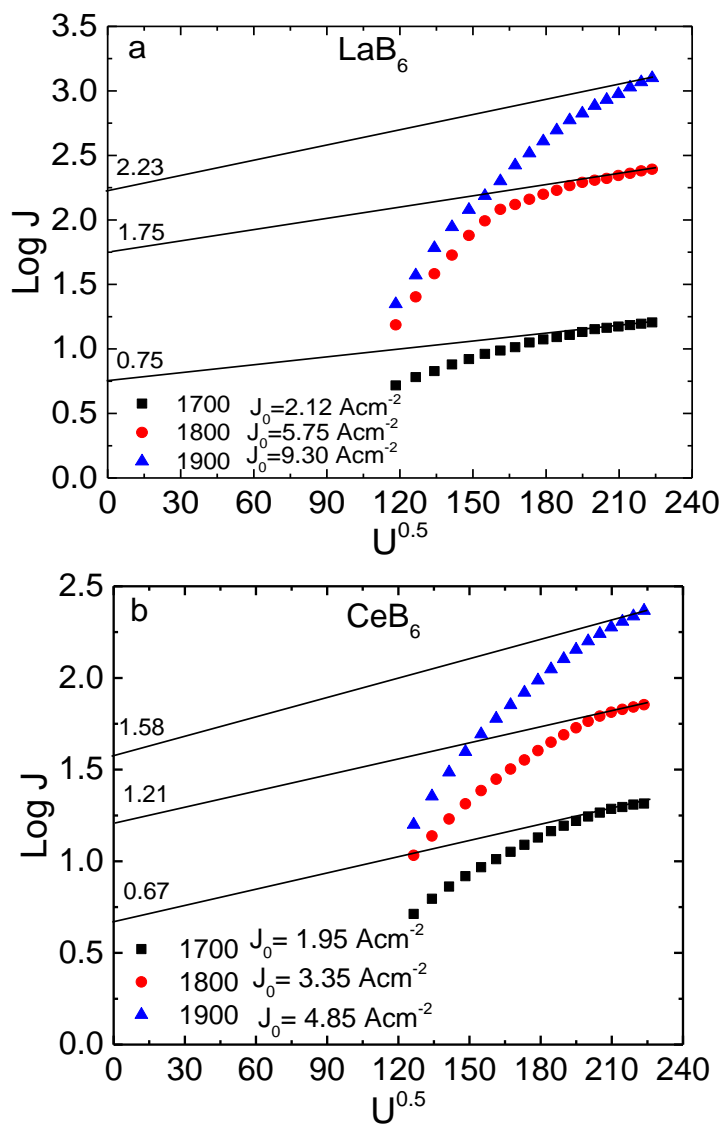

Fig. 6. The Schottky plot for $\mathrm{LaB}_{6}$ (a) and $\mathrm{CeB}_{6}$ (b) at three different temperatures 1700,1800 , and $1900 \mathrm{~K}, \mathrm{~J}_{\mathrm{o}}$ the current density at zero applied voltage.

The work function of the material has the primary responsibility for its emission tendency. The emission slope which can be defined as "the change of the current density per change in the cathode temperature $\Delta \mathrm{J} / \Delta \mathrm{T}\left(\mathrm{Acm}^{-2} \mathrm{~K}^{-1}\right)$ is an essential indicator for the material stability when studying $\mathrm{BB}$ effect. In the case of for $\left(\mathrm{Ba}, \mathrm{Ca}, \mathrm{Nd}\right.$, and $\mathrm{Ce}$ ) $\mathrm{B}_{6}$, materials with high work functions, a slow growth of the current density is introduced as a function of temperature, whereas in the other materials, which have low work functions, a sharp current density increase is observed (see Fig. 7). The estimated values of $\Delta \mathrm{J}$ range between 4.5 and $13.6 \mathrm{Acm}^{-2}$ for $\mathrm{BaB}_{6}$ to $\mathrm{GdB}_{6}$. Hence, the explored materials could be divided into two groups: the first one with $\Delta \mathrm{J}<7 \mathrm{Acm}^{-2}$, including ( $\mathrm{Ba}, \mathrm{Ca}, \mathrm{Nd}$, and $\mathrm{Ce}$ ) $\mathrm{B}_{6}$, and the second group of materials with $\Delta \mathrm{J}>10 \mathrm{Acm}^{-2}$, comprising ( $\mathrm{La}, \mathrm{Sm}, \mathrm{Pr}$, and $\mathrm{Gd}$ ) $\mathrm{B}_{6}$. The percentage of $\Delta \mathrm{J}$ for $\mathrm{BaB}_{6} / \mathrm{GdB}_{6}$ is $33 \%$, while for $\mathrm{BaB}_{6}, \mathrm{CaB}_{6}$ and $\mathrm{NdB}_{6}$ are 42,50 , and $59 \%$ respectively compared with $\mathrm{LaB}_{6}$.

The degradation of the cavity voltage is estimated from the model by solving the RF gun equivalent circuit. The results were in the range between 190 to $405 \mathrm{kV}$ for $\mathrm{BaB}_{6}$ to $\mathrm{GdB}_{6}$ respectively. The corresponding decrease of the electron beam energy ranged from 95 to $300 \mathrm{keV}$ for $\mathrm{BaB}_{6}$ to $\mathrm{GdB}_{6}$, respectively. This tendency followed the beam loading effect, TABLE III

SHIFT IN CATHODE TEMPERATURE AND CURRENT DENSITY

\begin{tabular}{ccccccccc}
\hline \hline & $\mathrm{CaB}_{6}$ & $\mathrm{BaB}_{6}$ & $\mathrm{LaB}_{6}$ & $\mathrm{CeB}_{6}$ & $\mathrm{PrB}_{6}$ & $\mathrm{NdB}_{6}$ & $\mathrm{SmB}_{6}$ & $\mathrm{GdB}_{6}$ \\
\hline $\mathrm{T}_{0}$ & 2240 & 2397 & 1783 & 1817 & 1745 & 1924 & 1766 & 1683 \\
$\Delta \mathrm{T}$ & 62 & 66 & 79 & 71 & 88 & 92 & 89 & 94 \\
$\Delta \mathrm{J}$ & 5.3 & 4.5 & 10.5 & 6.9 & 12.3 & 6.2 & 11.4 & 13.6 \\
\hline \hline
\end{tabular}


this is when the beam current emitted from the cathode during the pulse duration increase, the cavity voltage decrease. As a result, the energy of the electron beam extracted from the gun aperture decrease. Thus, it has a detrimental effect on the electron beam properties that injected into the following structures in the accelerator systems. An electron beam with stable energy is mandatory for any FEL applications [36]. The drops of the electron beam energy for $\mathrm{BaB}_{6}, \mathrm{CaB}_{6}$, and $\mathrm{NdB}_{6}$ compared to $\mathrm{LaB}_{6}$ was in the same ratio as the shift in the current density. Therefore, from the change of the cathode current density and extracted electron beam energy point of view, one can conclude that " $\mathrm{Ba}, \mathrm{Ca}, \mathrm{Nd}$, and $\mathrm{Ce}) \mathrm{B}_{6}$ are less affected by BB electrons compared with other hexaborides".

The emission slope for investigated $\mathrm{RAB}_{6}$ was calculated to be $(6.7,6.8,8.5$, and 9.8$) \times 10^{-2} \mathrm{Acm}^{-2} \mathrm{~K}^{-1}$ for $(\mathrm{Nd}, \mathrm{Ba}, \mathrm{Ca}$, and Ce) $\mathrm{B}_{6}$, respectively. While, the emission slopes are $(12.8,13.2$, 14.0, and 14.4) $\times 10^{-2} \mathrm{Acm}^{-2} \mathrm{~K}^{-1}$, for $(\mathrm{Sm}, \mathrm{La}, \mathrm{Pr}$, and $\mathrm{Gd}) \mathrm{B}_{6}$, respectively. Another fact found is that the relationship between the rising of cathode temperature and ramping current density was not linear. The expected ramping of beam current for $\left(\mathrm{BaB}_{6}, \mathrm{CaB}_{6}\right)$ and $\left(\mathrm{PrB}_{6}, \mathrm{GdB}_{6}\right)$ was two and three times the intail beam current before the $\mathrm{BB}$ electrons, respectively. This is seen in Fig. 3(a), where an increase in the current density causes an increase of heat deposition, and hence an elevation of the cathode temperature. For applications with high beam current (above $10 \mathrm{Acm}^{-2}$ ), the operational temperature of the cathode is high. As a result, the emission curve becomes sharper (Fig. 7). In the case of $\mathrm{LaB}_{6}$ the operational temperatures for 5 and $10 \mathrm{Acm}^{-2}$ are 1783 , and $1845 \mathrm{~K}$, assuming that the same change of cathode temperature occurred, it will cause a different shift in current density. $\mathrm{BaB}_{6}$ and $\mathrm{CaB}_{6}$ materials are hard to be used as a thermionic cathode for applications of high beam current because the elements would reach or approach their melting temperatures of 2508 and $2543 \mathrm{~K}$. indeed, operate the cathode material near its melting point will increase its evaporation rate. As a result, there will be a decrease in its lifetime and performance [20].

Lastly, (Nd, Ce, Sm, La, Pr, Gd) B 6 were candidate materials for high current density applications before reaching their melting points. $\mathrm{CeB}_{6}$ and $\mathrm{LaB}_{6}$ are extensively studied as a thermionic cathode material, but not the case for (Nd, Pr, Gd) $\mathrm{B}_{6}$ or a mix between hexaborides. It is reported that $\mathrm{LaB}_{6}$ emission performance improved when combined with $\mathrm{Ba}, \mathrm{Sr}$ [22], $\mathrm{Eu}$ [37], $\mathrm{Ce}$ in the form $\left(\mathrm{Ce}_{0.25} \mathrm{La}_{0.75} \mathrm{~B}_{6}\right)$ [38], $\mathrm{Pr}$ $\left(\mathrm{La}_{0.3} \mathrm{Pr}_{0.7} \mathrm{~B}_{6}\right)$ and $\mathrm{Nd}\left(\mathrm{La}_{0.3} \mathrm{Nd}_{0.75} \mathrm{~B}_{6}\right)$ [39]. Due to increasing the concentration of large hexaborides in $\mathrm{LaB}_{6}$ lattice, make inter compound electronic structure change and material density. Hexaborides in the form $\mathrm{RA}_{x} \mathrm{RA}^{*}{ }_{1-\mathrm{x}} \mathrm{B}_{6}$ are expected to give better performance, from the thermionic emission point of view with less work. However, further analysis of other physical and chemical properties are still needed before implementing them as the cathode material in real research or user facilities. As a good suggestion for this complex, $\mathrm{Ca}-\mathrm{LaB}_{6}$ could have less density and low work function and is thus expected to reduce the BB electrons in T-RF guns.

Overall based on this study, $\mathrm{BaB}_{6}, \mathrm{CaB}_{6}$, and $\mathrm{NdB}_{6}$ are expected to have less affect by $\mathrm{BB}$ electrons for low beam current applications compared with other materials. $\mathrm{NdB}_{6}$, $\mathrm{CeB}_{6}$, and $\mathrm{SmB}_{6}$ are candidates for high beam current

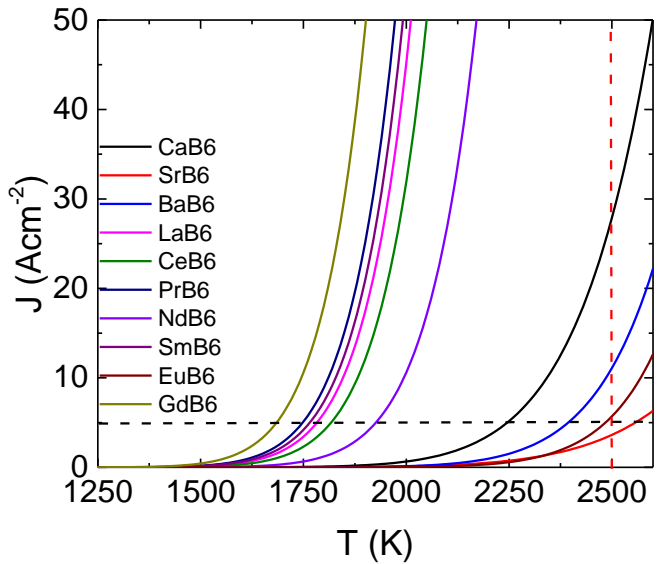

Fig. 7. The ideal emission curves for the hexaborides calculated using Richardson equation.

applications. Consequently, it is advisable to subject $(\mathrm{Ba}, \mathrm{Ca}$, $\mathrm{Nd}$, and $\mathrm{Sm}) \mathrm{B}_{6}$ to a real test with T-RF gun to compare their performance and its $\mathrm{BB}$ electrons effect with $\mathrm{LaB}_{6}$.

\section{Conclusions}

An extended evaluation model has been performed to explore the effect of $\mathrm{BB}$ electrons on ten hexaborides. The model includes tracing BB electrons inside a 4.5-cells T-RF gun using simulation codes to understand BB electrons behavior. Then the influence of cathode materials density on the stopping range and heat deposited was investigated using a semi-empirical equation. The work functions of $\mathrm{LaB}_{6}$ and $\mathrm{CeB}_{6}$ were experimentally determined and used in the model. Finally, the ramping of cathode temperature and current density with degradation of the cavity voltage and electron beam energy were estimated.

The results of stopping range and heat deposition revealed that light materials are expected to have less influence by $\mathrm{BB}$ electrons and vice versa. Also, based on the ramping of current density results, elements with higher work function have less effect by BB electrons. From the emission slope point of view, $\mathrm{RAB}_{6}$ can be arranged as $(\mathrm{Nd}, \mathrm{Ba}, \mathrm{Ca}, \mathrm{Ce}, \mathrm{Sm}, \mathrm{La}, \mathrm{Pr}, \mathrm{Gd}) \mathrm{B}_{6}$, which means materials with less emission slope are more stable against temperature and current density changes during the macropulse.

In conclusion, the present study suggests using of $(\mathrm{Ba}, \mathrm{Ca}$, $\mathrm{Nd}$,) $\mathrm{B}_{6}$ materials for T-RF gun employed in low beam current applications, because they are less affected by BB electrons: 42 , $50,59 \%$, respectively, compared with $\mathrm{LaB}_{6}$. However, for higher beam current applications $>10 \mathrm{Acm}^{-2},(\mathrm{Nd}, \mathrm{Ce}, \mathrm{Sm}) \mathrm{B}_{6}$ are recommended. The results also suggest that further work is needed on the $(\mathrm{Ca}, \mathrm{Ba}, \mathrm{Nd}, \mathrm{Sm}) \mathrm{B}_{6}$ compounds to verify their performance regarding their $\mathrm{BB}$ electrons effect in comparison with $\mathrm{LaB}_{6}$ and performance of these compounds mixed.

\section{ACKNOWLEDGMENT}

The author would like to thank K. Masuda, T. Kii and H. Zen from the Institute of advanced energy, Kyoto University, Japan, for their assistance, providing tools, programs, and equipment to accomplish this study.

\section{REFERENCES}

[1] S. V. Benson, J. M. J. Mady, J. Schultz, M. Marc, W. Wadensweiler, and G. A. Westenskow, "The Stanford MARK III Free Electron Laser," Nucl. Instr. Meth. Phys. Res., Sect., A 250, 39-43, (1986). Doi: 10.1016/01689002(86)90857-0 
[2] J. S. Fraser, R. L. Sheffield, E. R. Gray, P. M.Giles, R. W. Springer and V. A. Loebs, "Photocathode in Accelerator applications," in Proceedings of the 1987 Particle Accelerator Conference (IEEE, Washington, DC, 1987), pp. 1705-1709, (1987).

[3] Y. Zou, H. Li, M. Reiser, and P. G. Oshea, "Theoretical Study of Transverse Emittance Growth in a Gridded Electron Gun," Nucl. Instr. Meth. in Phys. Res., A 519, pp. 432-441, (2004). Doi: 10.1016/j.nima.2003.11.183

[4] K. Kasamsook, K. Akiyama, K. Nanbu, M. Kawai, F. Hinode, T. Muto, T. Tanaka, M. Yasuda, Y. Mori, and H. Hama, "Development of a Low Emittance DC Gun for Smith-Purcell Bwo FEL," Proceedings of $29^{\text {th }}$ FEL 2007, Novosibirsk, Russia, 417-420, (2007).

[5] M. Bakr, G. Vashchenko, M. Khojoyan, M. Krasilnikov, and F. Stephan, "Beam Dynamics Simulation for the Upgraded PITZ Photoinjector Applying Various Photocathode Laser Pulses" in Proc. $37^{\text {th }}$ Int. FreeElectron Laser Conf., Daejeon, 2015, pp. 501-504, (2015).

[6] H. Ohgaki, T. Kii, K. Masuda, M. Bakr, K. Higashimura, R. Kinjo, K. Yoshida, S. Ueda a, T. Sonobe, and Y.U Jeong, "Research activities on a MIR-FEL and table-top THz generation in Kyoto University," J. Korean Phys. Soc., 57, 2, pp.344-348, (2010). Doi.:10.3938/jkps.57.344

[7] C. B. McKee and J. M. J. Madey, "Computer simulation of cathode heating by back-bombardment in the microwave electron gun," Nucl. Instr. Meth. Phys. Res., Sect. A 296, 716-719, (1990). Dio: 10.1109/FEL.1989.716096

[8] H. Zen, T. Kii, R. Kinjo, S. Sasaki, T. Shiiyama, K. Masuda, and H. Ohgaki, "Beam Energy Compensation by RF Amplitude Control for Thermionic RF Gun and Linac Based mid-infrared FEL," in Proceedings of $11^{\text {th }}$ European Particle Accelerator Conference (Genoa, Italy), p. 13291331, (2008)

[9] K. Kanno and E. Tanabe, "Design of Backbombardment-less Thermionic RF Gun,” J. Appl. Phys. 41, pp. 62-64, (2002). Dio: 10.7567/JJAPS.41S1.62

[10] T. Tanaka, et al., "Simulation Study of a Thermionic RF gun for High brightness and Short Pulse beam" in Proceedings of the $21^{\text {st }}$ Particle Accelerator Conference (Knoxville, USA, May 16-20, 2005), p. 34993451, (2005).

[11] G. A. Westenskow J. M. J. Madey, L. C. Vmtro, and S.V. Benson, "Owner's manual for the Microwave Electron Gun," HEPL Technology Note, TN-86-1 (1986).

[12] L. Hongxiu, "Simulation studies on back bombardment of electrons in RF thermionic guns" Nucl. Instr. Meth. Phys. Res. A 302, 535-546, (1991). Doi: 10.1016/0168-9002(91)90372-W

[13] Y. Huang and J. Xie, "Measures to Alleviate the Back Bombardment Effect of Thermionic RF Electron Gun," in the proceeding of PAC 1991 IEEE (San Francisco, CA), Vol. 4, pp. 2017-2019, (1991).

[14] K. Shinto, H. Hama, F. Hinode, A. Miyamoto and T. Tanaka, "Three Dimensional Time-Doman Beam Simulation Study for a Thermionic RF Gun," in Proceedings of APAC (Gyeongju, Korea, pp. 297-299, (2004).

[15] J. M. D. Kowalczyk and J. M. J. Mady, "Back bombardment compensation in microwave thermionic electron guns," J. Phys. Rev. Spec. Top. Accel. Beams 17, 120402-9, (2014). Dio: 10.1103/PhysRevSTAB.17.120402

[16] E. Marc, E. Herniter, and W. Getty, "Temperature-Limited Electron Bombardment Heating Method," IEEE Trans. Plasma Sci. 19, 6, pp. 1279-1289, (1991). Dio: 10.1109/27.125052

[17] M. Bakr R. Kinjo, Y. W. Choi, M. Omer, K. Yoshida, S. Ueda, M. Takasaki, K. Ishida, N. Kimura, T. Sonobe, T. Kii, K. Masuda, and H. Ohgaki, "Back bombardment for dispenser and lanthanum hexaboride cathodes," J. Phys. Rev. Spec. Top. Accel. Beams 14, 060708 (2011). Dio.org/10.1103/PhysRevSTAB.14.060708

[18] M. Bakr, R. Kinjo, Y. W. Choi, M. Omer, K. Yoshida, S. Ueda, M. Takasaki, K. Ishida, N. Kimura, H. Zen, T. Sonobe, T. Kii, K. Masuda and $\mathrm{H}$. Ohgaki, "Comparison of the heating property of $\mathrm{LaB}_{6}$ and $\mathrm{CeB}_{6}$ by back bombardment effect in thermionic RF gun," J. Korean Phys. Soc., vol. 59, no. 51, pp. 3273-3279, (2011). Dio.org/ 10.3938/jkps.59.3273

[19] M. Bakr, M. Kawai, T. Kii, and H. Ohgaki, "CeB6: Emission Performance and Uniformity Compared With $\mathrm{LaB}_{6}$ for Thermionic RF Guns," IEEE T. E. D. 63, pp. 1326-1332, (2016). Dio: 10.1109/TED.2016.2520951

[20] J. M. Lafferty, "Boride Cathodes," J. Appl. Phys., 22, no. 3, pp. 299-309, (1951). Dio: 10.1063/1.1699946

[21] H. Zhang, J. Tang, Q. Zhang, G. Zhao, G. Yang, J. Zhang, O. Zhou, and L. C. Qin, "Field Emission of Electrons from Single $\mathrm{LaB}_{6}$ Nanowires," Adv. Mater. 18, pp. 87-90, (2006). DOI: 10.1002/adma.200500508
[22] M. Futamoto, M. Nakazawa, K. Usami, S. Hosoki, and U. Kawabe, "Thermionic Emission Properties of a Single Crystal $\mathrm{LaB}_{6}$ Cathode, "J Appl. Physics. 51, pp. 3869-3876, (1980). Dio: 10.1063/1.328132

[23] S. Otani, and Y. Ishizaw, "Single Crystals of Carbides and Borides as Electron Emitters," prog Crystal Growth and Charact. 23, pp. 153-177, (1991). Dio: 10.19009/jjacg.17.2_188

[24] H. Liu, X. Zhang, Y. Xiao, and J. Zhang, "The electronic structure and thermionic emission property of single crystal $\mathrm{SmB}_{6}$ ", Vacuum $145 \mathrm{pp}$. 295-298, (2017). Dio: 10.1016/j.vacuum.2017.09.015

[25] F. Qinghai, Z. Qinyuan, Z. Yanming, and D. Qiwei, "Field emission from a one-dimensional single crystalline $\mathrm{NdB}_{6}$ nanowires," J. of Rare Earths, V. 31, No. 2, pp. 145-148, (2013). Dio:10.1016/S1002-0721(12)60248-8

[26] H. Liu, X. Zhang, Y. Xiao, Y. Wang and J. Zhang, "The thermionic and field emission properties of single crystal $\mathrm{PrB}_{6}$ grown by floating zone method", Vacuum 151, pp. 76-79, (2018). Dio: 10.1016/j.vacuum.2018.02.015

[27] L.S. Dorneles, M. Venkatesan, M. Moliner, J. G. Lunney, and J. M. D. Coey, "Magnetism in thin films of $\mathrm{CaB}_{6}$ and $\mathrm{SrB}_{6}$ ", J. Appl. Phys. Let. V. 85, N. 26, pp. 6377-6379, (2004). Dio: 10.1063/1.1840113

[28] S. Zherlitsyn, B. Wolf, B. Luthi, M. Lang, P. Hinze, E. Uhrig, W. Assmus, H.R. Ott, D.P. Young, and Z. Fisk, "Elastic properties of ferromagnetic EuB6", Eur. Phys. J. B 22, pp. 327-333, (2001). Dio: 10.1007/BF01312802

[29] H. Liu, X. Zhang, Y. Xiao, and J. Zhang, "The electronic structures and work functions of (100) surface of typical binary and doped $\mathrm{REB}_{6}$ single crystals", Appl. Surf. Sci. 434, pp. 613-619, (2018). Dio: 10.1016/j.apsusc.2017.10.233

[30] H. Ohgaki, T. Kii, K. Masuda, T. Yamazaki, K. Yoshikawa, H. Zen, "Beam Charge Feedback System for Thermionic Cathode RF-Gun," Proceedings of PAC07, pp. 254-256, (2007).

[31] L. M. Young and J. H. Billen, "PARMELA," LANL, Technical Note LAUR-96-1835, 2002.

[32] K. Masuda, "Development of Numerical Simulation Code and Application to Klystron Efficiency Enhancement, "Ph.D. thesis, Kyoto University, (1998).

[33] T. Tabata, R. Ito, and S. Okabe, "Generalized Semiempirical Equations for the Extrapolated Range of Electrons," Nucl. Instrum. Methods Phys. Res. 103, 85-91, (1972). Dio: 10.1016/0029-554X(72)90463-6

[34] O. W. Richardson, "Electron Theory of Matter," Philips Mag. 23, pp. 594-627, (1912).

[35] E. K. Storms and B. A. Mueller, "A study of surface stoichiometry and thermionic emission using LaB,", J. Appl. Phys. 50, 3691-3698 (1979). Dio: $10.1063 / 1.326323$

[36] H. Ohgaki, T. Kii, K. Masuda, M. A. Bakr, K. Higashimura, R. Kinjo, K. Yoshida, S. Ueda, T. Sonobe, H. Zen, and Y. U. Jeong, "Status of the MIR-FEL Facility in Kyoto University," Proceedings of $31^{\text {st }}$ international FEL Conference, pp.572-575, (2009).

[37] E. K. Storms, "A contribution to the theory of high-temperature vaporization and electron emission: Application to neodymium hexaboride and lanthanum hexaboride," J. Appl. Phys. 52(4), 2961-2965, (1981). Dio: 10.1063/1.329037

[38] S. Y. Ning, T. Litaka, X. Y. Yang, Y. Wang, J. Zhao, Z. Li, and J. Zhang, "Enhanced thermionic emission performance of $\mathrm{LaB}_{6}$ by Ce doping," J. Alloys and compounds, V. 760, pp. 1-5, (2018). Dio: 10.1016/j.jallcom.2018.05.154

[39] P.H. Schmidt and D.C. Joy, "Low work function emitter hexaborides", J. Vac. Sci. Technol. 15 1809-1810, (1978). Dio: 10.1116/1.569847

Mahmoud Bakr was born in Asyut, Egypt, in 1978. He received the M.S. degrees in physics from Assiut University, Asyut, in 2007, and the Ph.D. degree in particles and accelerators physics from Kyoto University, Kyoto, Japan, in 2011. He was a PD. Fellow with PITZ, Zeuthen, Germany, from 2014 to 2015. Since September 2015- until now he is a researcher at Institute of Advanced Energy, Kyoto University, Kyoto. His current research interests include electron guns, accelerators, FEL applications, fission and fusion systems, and Plasma physics. Hideaki Ohgaki (M'06) received the D.Eng. degree in radiation measurement from Kyushu University, Fukuoka, Japan, in 1988. He is currently a Professor with the Institute of Advanced Energy, Kyoto University, Kyoto, Japan. His current research interests include electron accelerators, quantum radiations (i.e., free electron lasers and laser Compton backscattering photons), and radiation measurement.
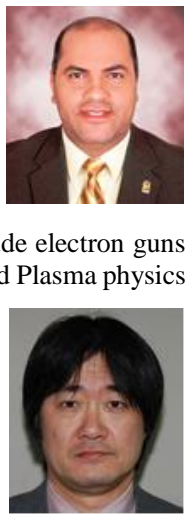